\title{
Traction alopecia: the root of the problem
}

This article was published in the following Dove Press journal:

Clinical, Cosmetic and Investigational Dermatology

\section{Victoria Billero \\ Mariya Miteva}

Department of Dermatology and Cutaneous Surgery, University of Miami School of Medicine, Miami, FL, USA
Correspondence: Victoria Billero Department of Dermatology and Cutaneous Surgery, University of Miami Miller School of Medicine, 1600 N.W. $10^{\text {th }}$ Avenue, RMSB Building Room 2023C, Miami, FL 33136, USA

Tel +l 3052435523

Fax +I 3052435810

Email v.billero@med.miami.edu

\begin{abstract}
Traction alopecia (TA) affects one-third of women of African descent who wear various forms of traumatic hairstyling for a prolonged period of time. The risk of TA is increased by the extent of pulling and duration of traction, as well as the use of chemical relaxation. The frequent use of tight buns or ponytails, the attachment of weaves or hair extensions, and tight braids (such as cornrows and dreadlocks) are believed to be the highest risk hairstyles. TA can also occur in the setting of religious and occupational traumatic hairstyling. In its later stages, the disease may progress into an irreversible scarring alopecia if traumatic hairstyling continues without appropriate intervention. The most common clinical presentation includes marginal alopecia and non-marginal patchy alopecia. A clue to the clinical diagnosis is the preservation of the fringe sign as opposed to its loss in frontal fibrosing alopecia (FFA). Dermoscopy can be helpful in the diagnosis and can detect the ongoing traction by the presence of hair casts. Histopathology can distinguish TA from alopecia areata, FFA, and patchy central centrifugal cicatricial alopecia. Currently, there is no cure. Therefore, it is imperative that clinicians educate high-risk populations about TA and those practices that may convey the risk of hair loss.
\end{abstract}

Keywords: hair loss, alopecia, dermoscopy, trichoscopy, traction alopecia, African-American

\section{Introduction}

The prevalence of traction alopecia (TA) remains high in communities that practice tight braiding of the hair and, especially, when "relaxer" chemical treatments are used to straighten hair of the African type. ${ }^{1}$ In fact, one-third of women of African descent are affected. ${ }^{2}$ It is now generally agreed upon that the extent of pulling and the duration of traction increase the risk of TA and that treated hair may be less resistant to traction. ${ }^{3}$

In the early stage, patients typically present with patches of non-scarring hair loss along the area of the scalp that is undergoing tension. The hair loss can occur at any area of the scalp depending on the configuration of the hairstyle. Broken hairs and pustules within the follicles are often appreciated. ${ }^{4}$

In its later stages, the disease may progress into an irreversible scarring alopecia if traumatic hairstyling continues without appropriate intervention. Patients may also report tenderness, itching, paresthesias, and headache. ${ }^{5}$

In this review, we summarize the current literature about TA and discuss how to improve upon patient education, prevention, and care.

\section{History}

The entity today known as TA has been independently identified and described many times. In 1907, Trebitsch, ${ }^{6}$ an Austrian dermatologist, reported a characteristic marginal 
temporoparietal alopecia among Greenlandic women who wore their hair in a traditional tight coiffure arranged on the crown of the head (Figure 1) but absent among Greenlandic women whose hair was arranged in looser, European styles. He attributed this alopecia to native hairstyling practices and termed this entity "alopecia Groenlandica." ${ }^{6}$ Hjorth, studying this same population in 1957, noted a symmetrical baldness or thinning beginning at the hairline and accompanied by follicular atrophy with patchy areas of perifolliculitis. Interestingly, he noted the retention of "a thin straggling strip of hair" at the distal margin of the zone of alopecia as a characteristic of this disorder. ${ }^{7}$ This is reminiscent of the "fringe sign" reported by Samrao et al in $2011 .^{8}$ In the years following Trebitsch's initial description, many other investigators reported syndromes of hair loss attributable to excessive chronic traction.

In 1931, Aramaki reported a similar syndrome of marginal alopecia in Japan, which he attributed to traditional

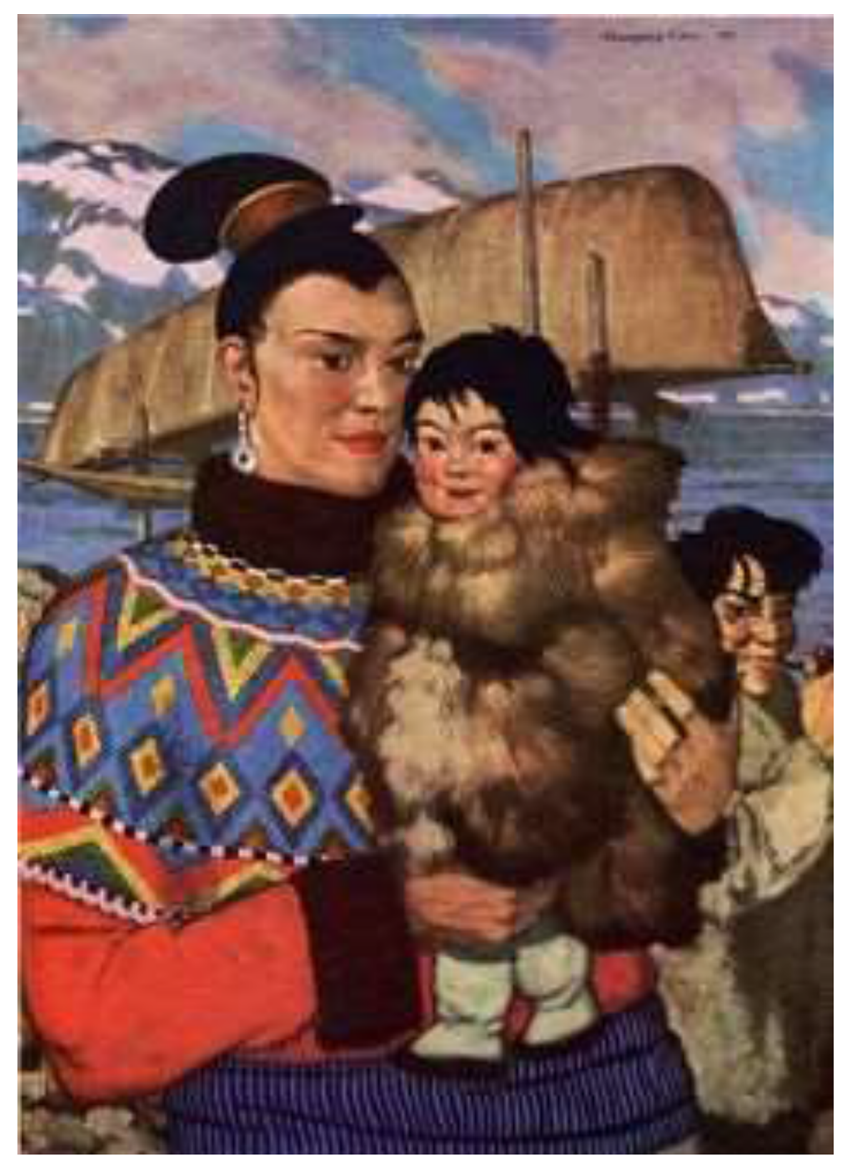

Figure I Painting “Greenland Mother” by W Langdon Kihn (1898-1957), showing a Greenlandic Inuit woman holding her baby. Note that her hair is worn in a tight coiffure arranged at the top of her head. Traumatic marginal alopecia can be appreciated, as was described by Trebitsch in 1907 as "alopecia Groenlandica." From: National Geographic, October 1949, page 486. Public access. hairstyles of that country and which he termed alopecia atrophica symmetrica temporalis. ${ }^{9}$ Other investigators in that country described syndromes of marginal TA that were primarily frontal or parietal in origin, with the distribution of alopecia differing with traditional hair styles in the different regions of Japan. ${ }^{9}$ Saboraud described frontal alopecia among French peasant women who wore their hair in tight chignons on the top of the head, which he termed alopecia liminaire frontale, though he did not attribute the hair loss to traction per se. ${ }^{7}$ Balina, an Argentine, was the first to propose a link between the initial stages of the disease with inflammation, pustules, and crusting and the later atrophic sequelae reported by Saboraud. He was also among the first to discern that mechanical traction was the cause of hair loss in these patients. ${ }^{10,11}$

For most of the 20th century and into the present, research into TA has focused on its predominance amongst women of African descent due to very tight braiding and aggressive chemical and thermal treatment of hair. In 1941, Spencer published a series of four African-American women presenting with bilateral temporal alopecia, all of which endorsed a history of having worn their hair in very tight braids. ${ }^{11}$ In 1958, Savill described an interaction between new brush technology and permanent hairstyling techniques that resulted in traction alopecia in a series of English patients. ${ }^{12}$

\section{Epidemiology Prevalence}

There is a paucity of data concerning the prevalence of traction alopecia among the general population. The data may be underreported based on cultural acceptance of the normality of hair loss associated with certain hairstyles. For that reason, investigation of the effects of cultural practices on TA risk is of essential importance.

One study of black adults presenting to a general dermatology clinic in London found traction alopecia to have a prevalence of $1.0 \% .{ }^{13}$ Another investigator reported TA to have a prevalence of $37 \%$ among women presenting to a primary care center in Cape Town, South Africa. ${ }^{14}$ An industry study of African women volunteers found a prevalence of $33 \% .{ }^{2}$ It is likely that the prevalence of TA ranges widely between populations with similar levels of genetic risk due to differences in hairstyling practices.

In conclusion, it is clear that the prevalence of TA is highest among women, including children, of African descent, due to both mechanical characteristics of the curved African hair follicle and cultural hairdressing practices. TA is much more common among women than men. ${ }^{15}$ 


\section{Association with specific hair morphology}

The hair of persons of African descent is uniquely distinct from the hair of persons originating in European and Asian populations. ${ }^{16}$ There are several factors that make African hair more susceptible to chronic mechanical trauma.

1. On transverse sections, the African hair shaft has an elliptical or "kidney-like" shape, whereas the hair of Caucasians and Asians has a uniformly circular shape on transverse sections. ${ }^{17}$

2. The African hair shaft has an asymmetrical position. ${ }^{17}$ The African hair follicle is curved at its insertion into the dermis and exhibits retro-curvature at the level of the follicular bulb. This is thought to be responsible for the helical morphology of the African hair follicle. ${ }^{18,19}$

3. The follicular bulb is asymmetrically curved resembling a golf club.

4. The hair follicle is helically shaped with each concave and convex turn contributing to geometric points of weakness. ${ }^{18,19}$

The axial asymmetry and helical shape lead to the presence of geometric points of weakness, which make African hair more susceptible to breakage during combing and to the development of TA secondary to tight hairstyles that subject the hair shaft to prolonged mechanical trauma. ${ }^{17}$

\section{Association with chemical relaxation}

Certain hairstyles convey a particularly high risk of TA. The frequent use of tight buns or ponytails, the attachment of weaves or hair extensions, and tight braids (such as cornrows and dreadlocks) are believed to be the highest risk hairstyles. The risk of these hairstyles contributing to TA is increased when the patient has undergone chemical relaxation of their hair. ${ }^{1}$ Chemical relaxation of the hair through interruption of disulfide bonds weakens the hair shaft, and the experience of a "stinging" association during the relaxing process has been identified as predicting a higher risk of future TA. Only $18.9 \%$ of patients suffering TA denied ever experiencing painful symptoms during or following hairdressing $g^{3,20}$ Among patients who continue to wear high-risk hairstyles and repeatedly use chemical relaxers, the prevalence of TA increases over time. In a study at a South African school, the prevalence of TA in schoolgirls was found to be $8.6 \%$ among first-year students and $21.7 \%$ among those girls in the last year of school. ${ }^{21}$

\section{Geographic variations}

Risk factors for TA appear to be similar between African and African-American populations..$^{22}$ The association between TA and practices that weaken the hair shaft or subject it to high levels of traction supports the hypothesis that TA is primarily caused by mechanical force. ${ }^{21}$

\section{Traumatic hair styles}

TA has been associated with numerous types of hairstyling related to cultural, religious, and occupational practices. Table 1 summarizes the different traumatic hairstyles and their associated patient population(s).

\section{Cultural practice}

People of African descent wear many types of hairstyles that put them at increased risk for developing TA. The hairstyles most commonly associated with TA in this patient population include braids, including cornrows, weaves, and dreadlocks. ${ }^{23}$ Khumalo et al reported an increase risk of developing TA in Africans who combine these traumatic hairstyles in the setting of chemically relaxed hair. ${ }^{3,21}$ Chemically relaxed hair

Table I Summary of traumatic hairstyles and their associated patient populations

\begin{tabular}{lll}
\hline Hairstyle & Hairstyle (description) & Associated patient population(s) \\
\hline
\end{tabular}


Table I (Continued)

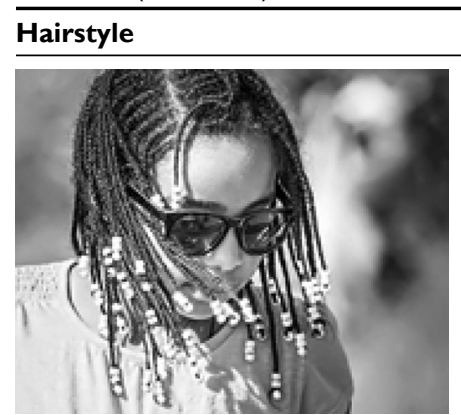

Plastic beads attached to braids

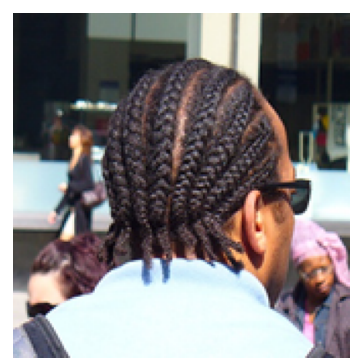

Braids, cornrows

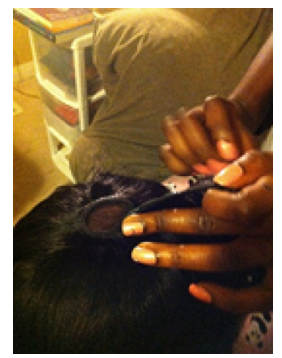

Hair weave

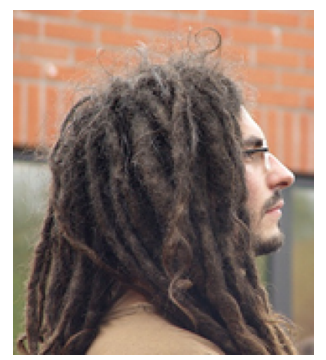

Dreadlocks

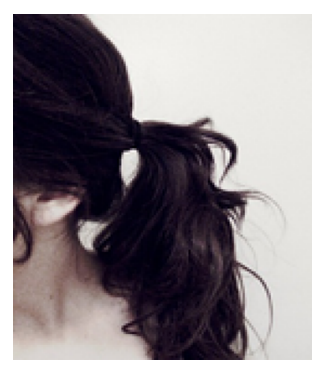

Ponytail
Hairstyle (description)

Hair is woven through plastic beads and secured at the distal end of the braid

Hair is separated into sections linearly along the frontal scalp. Within each of these sections, three parts of hair are pulled tightly from the sides of the scalp in order to weave the sections down from the frontal to the occipital scalp

The addition of synthetic or human hair that is either sewn onto the natural hair that has been braided into cornrows or glued onto the base of the hair

All of the hair is sectioned into squares. Each section of hair is held away from scalp while the hair is combed back toward the scalp with a comb, teasing, and knotting it up. The section is then secured with two rubber bands, one at the scalp and one at the distal end. Then each section is twisted or rolled

One or more sections of hair are pulled together and held together by a hair accessory near the scalp, usually an elastic band
Associated patient population(s)

Men, women, and children of African descent

Men, women, and children of African descent

Men and women of African descent

Men and women of African descent, Rastafarian, white counterculture

Hispanic women, athletic women

(Continued) 
Table I (Continued)

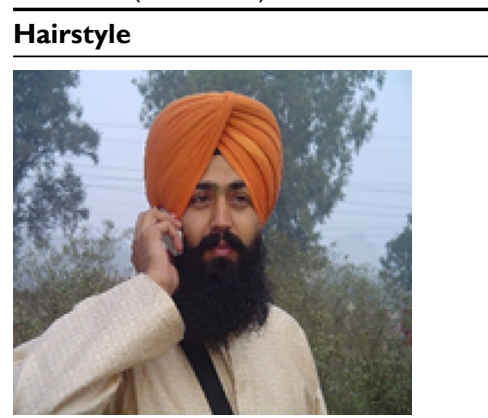

Turban, Sikh man

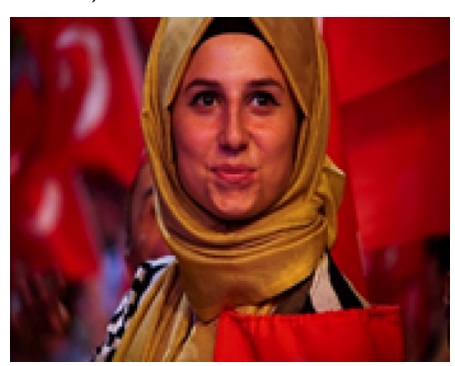

Turban, Turkish woman

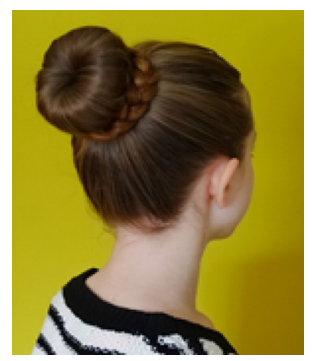

Bun

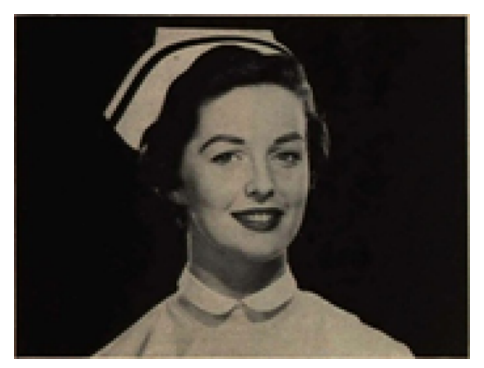

Depending on the shape of the cap, it is tightly secured by bobby pins at the parietal and/or occipital scalp

Associated patient population(s)

All of the hair is pulled tightly together and twisted before being tied off to sit on the frontal scalp. The turban is then wrapped tightly around the hair and the head

The first layer of the turban is securely wrapped around the hair and head. The second layer is wrapped on top of the first layer

All of the hair is pulled back tightly away from the face, twisted at the scalp, and wrapped around itself in a coil on the top, or the back of the head, or at the occipital scalp. It is secured with bobby pins, elastic bands, pencils, or barrettes
Sikh men and some women

Islamic women

\section{Ballerinas, sumo wrestlers}

Nurses in developing countries as well as in Japan and South Korea

Nurse's cap

Note: Images, in descending order: African girl braids, photograph by Wikimedia user Cestmoicarisse, distributed under a CC-SA 4.0 license. License at https:// creativecommons.org/licenses/by-sa/4.0/. Box braids by Wikimedia user Randen Pederson, available under a CC-BY 2.0 Creative Commons license, available at https:// creativecommons.org/licenses/by/2.0/deed.en. Cornrows, photograph by Wikimedia user David Shankbone, distributed under a CC-BY 2.5 license. License available at https://creativecommons.org/licenses/by/2.5/. Closure of netting weave process, photograph by Wikimedia user Kuteyiay, distributed under a CC-SA 3.0 license. License available at https://creativecommons.org/licenses/by-sa/3.0/. Man with dreadlocks, photograph by Wikimedia user Melimama, distributed under a CC-SA 2.0 license. License available at https://creativecommons.org/licenses/by-sa/2.0. Ponytail black hair, photograph by Wikimedia user Nicki Varkevisser, distributed by a CC-BY 2.0 license. License available at https://creativecommons.org/licenses/by/2.0/. Sikh wearing turban, photograph by Wikimedia user Harkanwal Singh, distributed under a CC-BY-SA 2.5 license. License available at https://creativecommons.org/licenses/by-sa/2.5/. Young Turkish woman, photograph by Wikimedia user Mstyslav Chernov, distributed by a CC-BY-SA 4.0 license. License available at https://creativecommons.org/licenses/by-sa/4.0/. Circumbraided donut bun, photograph by Wikimedia user Stilfehler, distributed under a CCBY-SA 3.0 license. License available at https://creativecommons.org/licenses/by-sa/3.0/. Image of nurse, from "The Canadian Nurse" (1905). This image is in the public domain according to contributing organization, the University of Ottawa. Information at https://www.flickr.com/photos//26377022@N07/14783/51983. 
is a commonly practiced styling technique producing a more straight and soft appearance and can be achieved through different processes. Lye relaxers contain sodium hydroxide and non-lye relaxers contain guanidine hydroxide, both of which use the hydroxide molecule to cleave the disulfide bond in the hair fiber. ${ }^{1}$ These chemical straighteners reduce the tensile strength of the hair follicle ${ }^{24}$ and increase hair brittleness, ${ }^{25}$ which contribute to hair loss when compounded by mechanical stress of traumatic styling. However, the traction exerted on the hair root by these traumatic hairstyles is enough to cause alopecia in a background absent of chemical relaxers. ${ }^{26}$ These hairstyles are utilized in this patient population because they contribute to hair manageability, flexibility, and appearance while also providing a means for celebration of cultural heritage. ${ }^{23}$

Similarly, Samrao et $\mathrm{al}^{8}$ reported on the increased risk of developing traction alopecia in Hispanic women who wore their hair in a tight ponytail for many years. The association was seen in Hispanic women with long, thick hair and presented with areas of hair loss primarily on the frontal and temporal scalp but also, less frequently, on the vertex and occipital scalp.

\section{Religious practice}

The literature has noted TA in association with religious practices. Sikhism is a religion originating in the Punjab region of India, which prohibits its men and women followers from cutting their hair to convey respect for God's creation of man as he was intended. As a child, ranging from 11 to 16 years of age, the Sikh men participates in a ceremony called "dastaar bandi" in which he tries on his first turban. From this time onward, the Sikh men will tightly twist all of his hair into a knot that sits on the frontal scalp. ${ }^{27}$ Then he will wrap a turban tightly around the hair to cover the top of the head which will be worn for 24 hours before being removed so the hair can be combed. ${ }^{28}$ Karimian-Teherani et al reported on two formerly Sikh brothers who wore turbans since childhood who moved to Austria aged 12 and 19 years and removed their headgear after rescinding the religion. They presented with sharply demarcated band-like scarring alopecia localized to the frontal hairline. ${ }^{29}$ Submandibular alopecia can also occur as the Sikh men tie their beards into tight knots that sit on the chin. ${ }^{28}$ Moreover, turban-wearing is commonplace in Islamic countries and has become increasingly popular in Turkey over the last three decades. ${ }^{30}$ In a passage from the Qur'an (7: 31), Muhammad exhorts, "O Children of
Adam! Wear your beautiful apparel at every time and place of prayer" and therefore, the bare head is considered among the "acts which betray self-respect," or khawarim al-muru'ah. The turban that Turkish women wear is different from that of the Sikh men, consisting of two layers, the first of which is securely wrapped around the hair and head with the second layer wrapped on top of the first. In the study conducted by Polat, Turkish women who wore their turban for less than 10 years were noted to have frontal alopecia, whereas Turkish women who wore their turban for more than 10 years were noted to have extension of hair loss into the fronto-parietal and fronto-temporal regions. ${ }^{30}$

\section{Occupational practice}

Trüeb reported on three women who presented with localized occipital alopecia in the context of twisting the hair into tight bun, proposing "chignon alopecia" as a new entity. ${ }^{31}$ Similarly, TA in a ballerina who wore her hair in an uncomfortably tight bun to dance class 4 days a week for 13 years presented with symmetrical temporal patches of hair loss. ${ }^{32}$ To cover up the patches of hair loss, the ballerina began wearing a 1.5-pound hairpiece every day for 2 years, subjecting her to greater traction and resulting in aggravation of hair loss. Additionally, in a report studying 143 South Korean nurses, seven developed localized parieto-occipital alopecia at the site where the cap was attached to the scalp by two bobby pins for 8 hours a day with a 9.8 years average duration of cap wearing. ${ }^{5}$

\section{Children and adolescents}

In the study by Wright et al, 201 caregivers of African girls aged $1-15$ years reported that within the past 12 months, $81 \%$ wore ponytails, $67 \%$ wore braids, and $49 \%$ wore cornrows. ${ }^{22}$ There was a significant risk of developing hair thinning along the hairline in the girls who wore cornrows within the last 12 months, which had a stronger association after controlling for use of chemical relaxers. ${ }^{22}$ Oftentimes, children of African descent will attach plastic beads and barrettes to their braids, which add additional traction. Samrao et al reported that Hispanic women who presented with TA began wearing tight ponytails in childhood or their teenage years. ${ }^{8}$

Sikh boys wear their hair and turbans very tightly to avoid loosening while playing, increasing the degree of traction on the hair shaft beginning in adolescence. ${ }^{33}$ As previously mentioned, the two formerly Sikh men presenting in Austria had sharply demarcated scarring alopecia of the frontal hairline at the age of 12 and 19 years. ${ }^{29}$ 


\section{Pathogenesis}

The hair loss seen in TA is thought to be caused by the exertion of excessive pulling forces, leading to mechanical damage of the hair follicles. ${ }^{3}$ The damage induces an inflammatory response, which presents as perifollicular erythema with pustules and/or papules in areas of traction. ${ }^{34}$ Chronic and repeated traction causes repeated follicular damage and eventually hair loss. ${ }^{3}$

\section{Clinical features and diagnosis}

The earliest clinical sign of TA is perifollicular erythema that develops into a folliculitis characterized by perifollicular pustules and papules. ${ }^{8,35}$ In its later stages, the disease evolves into a scarring alopecia with decreased follicular markings. ${ }^{8}$ The most common sites of hair loss are the frontal and temporoparietal areas, although any area of the scalp can be affected depending on the hairstyle worn (Figure 2). ${ }^{35}$ Marginal traction alopecia refers to hair loss and thinning that is seen along the frontal and temporoparietal margin of the hairline. ${ }^{36}$ Marginal TA is often accompanied by a strip of thin hair at the distal end of the patch of alopecia that is referred to as "the fringe sign" (Figure 3 ) ${ }^{8}$ Non-marginal, or patchy, alopecia is another variant of TA that refers to patches of hair loss and thinning that occur on less commonly affected areas of the scalp that can occur secondary to hair wefts, hair pins, or clips. For example, chronic use of hair wefts, which are a component of weaves, have been described to cause a "horseshoe" pattern of hair loss. ${ }^{36}$ Additionally,

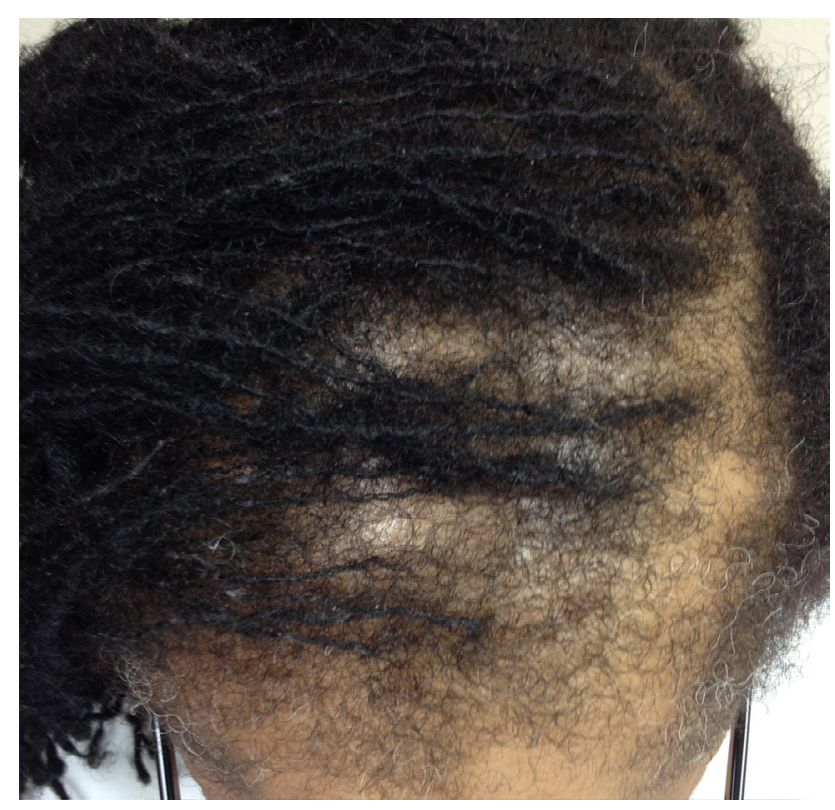

Figure 2 Biopsy-proven traction alopecia involving the frontal and parietal scalp.

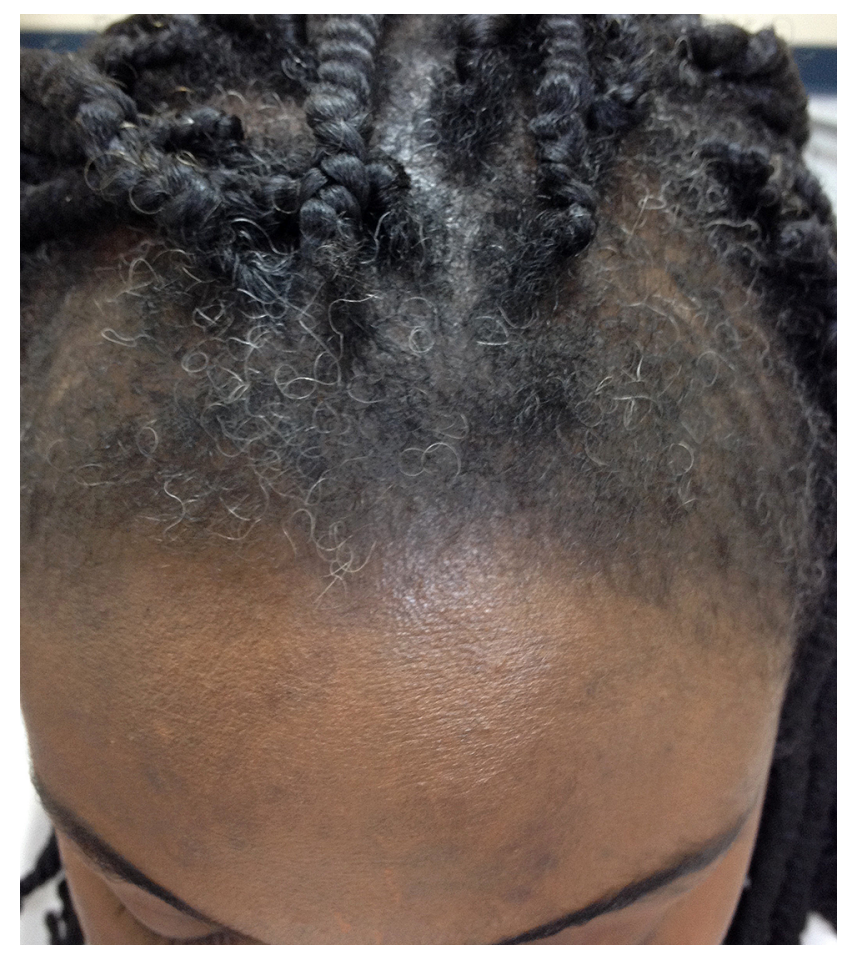

Figure 3 Marginal traction alopecia in patient with braids.

submandibular alopecia has been reported in Sikh men who tie their beard hair in a tight knot on their chin. ${ }^{28}$

Trichoscopy of patients with both marginal and nonmarginal distributions of TA will demonstrate 1) reduced hair density with absence of follicular openings ${ }^{37}$ or 2) absence of hairs with preserved in-brown-outlined follicular openings that correspond on pathology to the pigmented basal cell layer of follicular infundibulum (Figure 4). If there are any hairs remaining in the patches, they are exclusively of vellus origin. Patches of acute TA can present with broken hairs at different length in similarity to trichotillomania (Figure 5). Numerous hair casts, yellowish-white cylinders that accumulate around traumatized hair shafts, may be appreciated on dermatoscopy at the border of the area of hair loss (Figure 6). They slide easily along the hair shaft and correspond on pathology to the desquamated root sheaths. Their presence indicates the persistence of mechanical traction on the affected hair shafts. ${ }^{37,38}$

\section{Histopathology}

Early TA is rarely biopsied because patients usually seek help late when the patches are devoid of hairs and they see no regrowth. The features are similar to those in trichotillomania and consist of increased catagen/telogen count (telogen escape of traumatized follicles), pigment casts, and trichomalacia. 


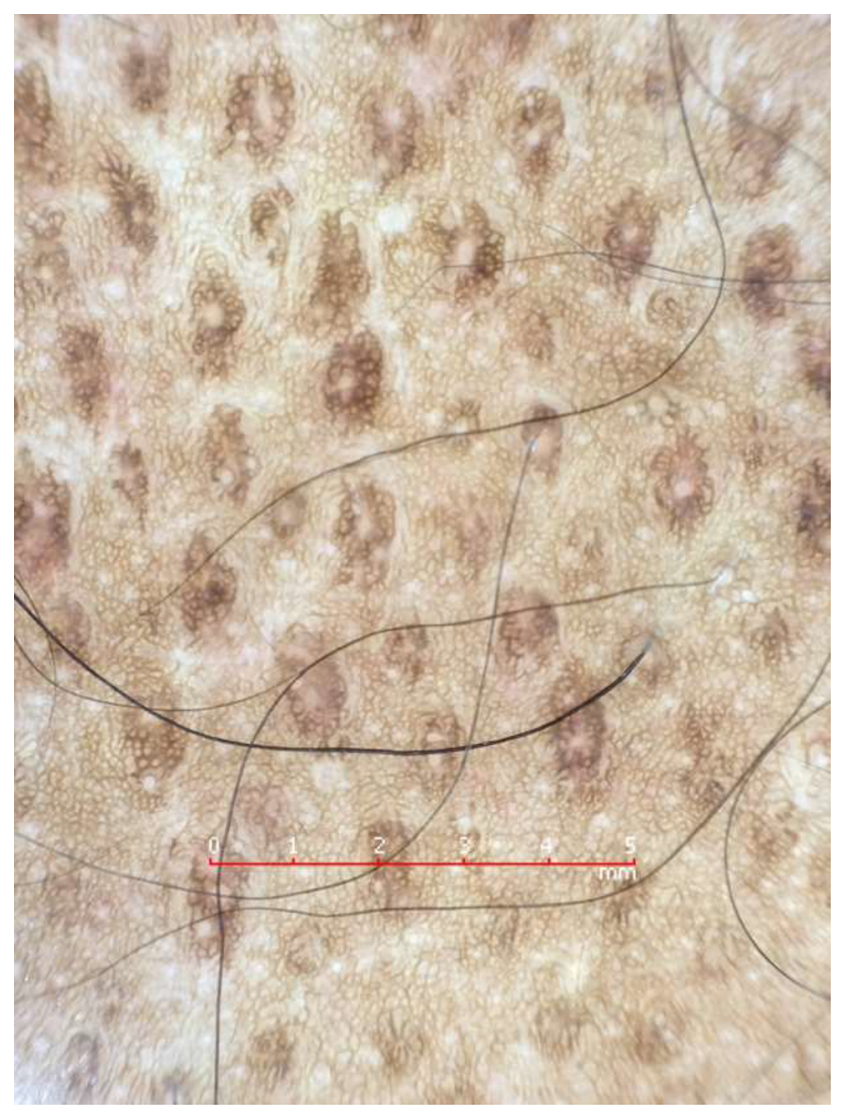

Figure 4 Trichoscopy of alopecic patch in traction alopecia shows only individual hairs with preserved marking of follicular openings outlined in brown that correspond to the pigmented basal cell layer of the infundibula.

\section{Late TA}

As the disease progresses into a scarring alopecia, there is an appreciated loss of terminal hair follicles or "follicular drop out" ${ }^{\$, 39}$ (Figure 7). The terminal hair follicles appear to be replaced by fibrotic fibrous tracts. The vellus hairs are intact, resulting in a decreased ratio of terminal to vellus-sized hair. ${ }^{8}$ There is preservation of the sebaceous glands and no perifollicular inflammatory infiltrate ${ }^{29}$ (Figure 8).

\section{Differential diagnosis}

In its early stage, patients with TA typically present with patches of non-scarring hair loss along the area of the scalp that is undergoing tension, which can mimic trichotillomania and alopecia areata by the presence of non-scarring alopecia and broken hairs. In the late stage, there are smooth hairless patches with follicular drop out, which need to be distinguished from scarring alopecias such as frontal fibrosing alopecia (FFA) and patchy central centrifugal cicatricial alopecia (CCCA). Distinctive features on clinical examination,

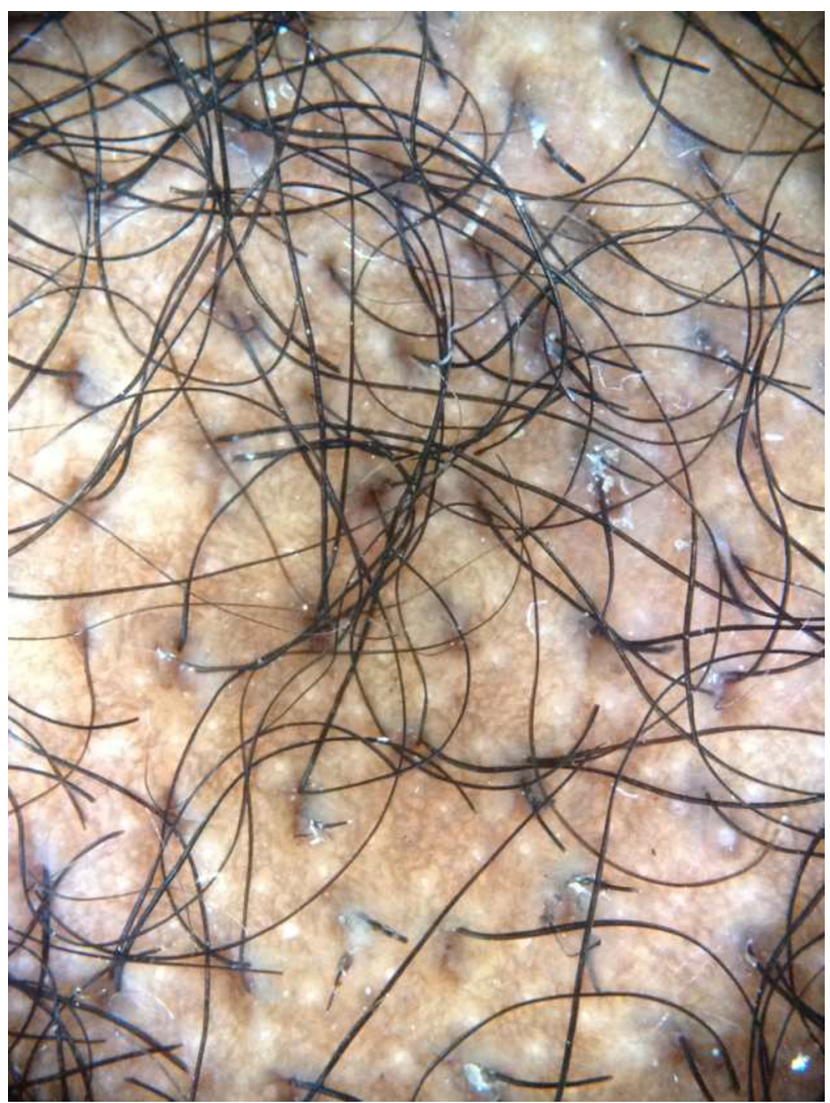

Figure 5 Trichoscopy of acute traction alopecia demonstrates black dots and broken hairs at different length. In this example, the patient is presented with marginal hair loss after removal of a glued wig.

trichoscopy, and pathology allow for the correct diagnosis (Table 2).

\section{Management}

Chronic TA may, in its later stages, develop into an irreversible scarring alopecia not remediable to therapy. Therefore, it is imperative that clinicians educate high-risk populations about TA and those practices that may convey the risk of hair loss. Mirmirani and Khumalo proposed two slogans, "Tolerate pain from a hairstyle and risk hair loss" and "No braids or weaves on relaxed hair," in order to bridge patient-provider knowledge gaps in the avoidance of traction alopecia. ${ }^{40}$ Because most cases of traction alopecia can be reversed, ${ }^{23}$ if the appropriate interventions are taken at an early stage of the disease; clinicians must be vigilant and proactive in their care of patients who may be at risk. The key to management at any stage in the disease course is the relief of traction exerted upon the hair shaft by the loosening of traumatic hairstyles. Avoidance of chemical and thermal treatment of hair is also recommended, as well as the avoidance of combining traumatic 


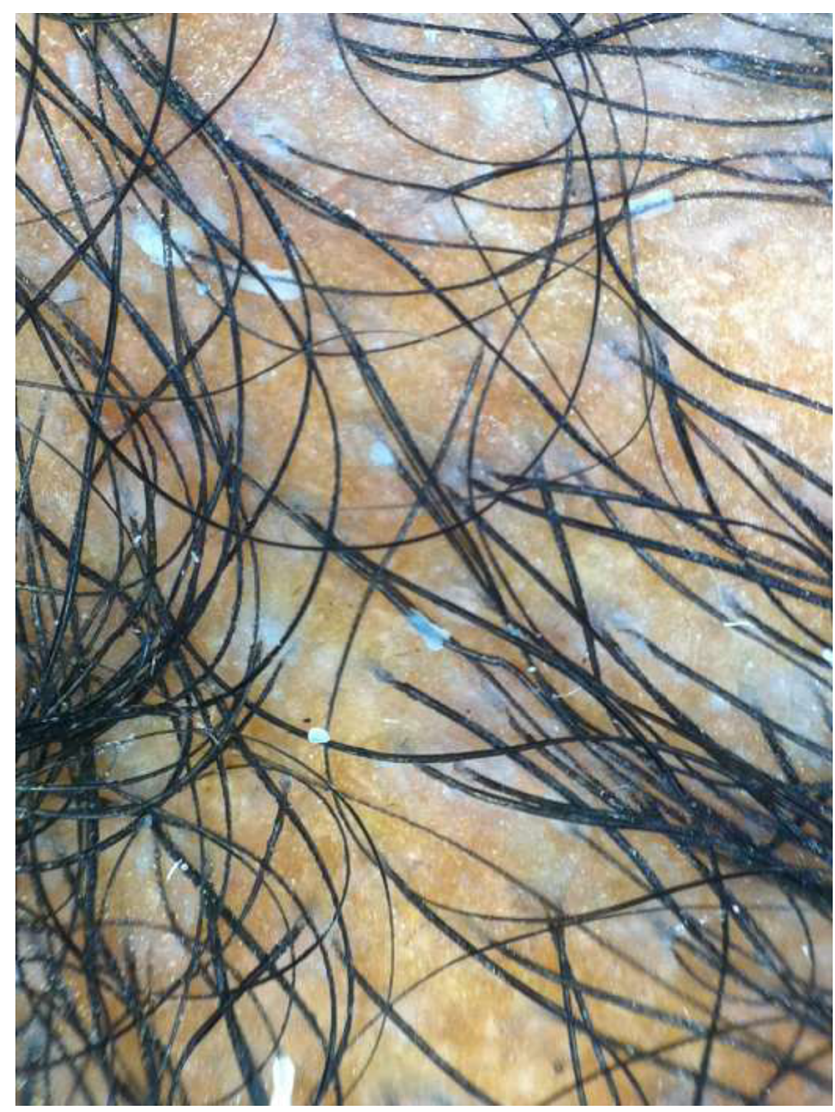

Figure 6 Trichoscopy of traction alopecia demonstrates cylindrical hair casts along several hair shafts.

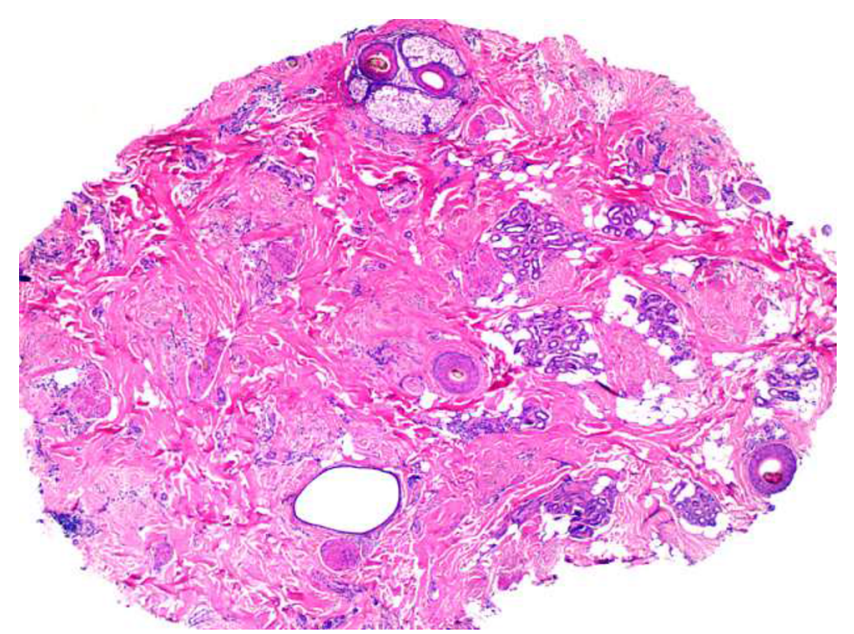

Figure 7 Histology of traction alopecia. On horizontal sections at the level of the low follicular level, there is altered follicular architecture due to areas of follicular drop out. There are only four follicles (hematoxylin and eosin, $\times 2$ ).

hairstyling with chemically and thermally treated hair. ${ }^{35}$ The earliest clinical sign of TA is perifollicular erythema, which may be followed by the development of folliculitis characterized by pustules and papules. ${ }^{8,41}$ Initial medical management is directed at combating these inflammatory effects through the use of topical and intralesional corticosteroids applied to

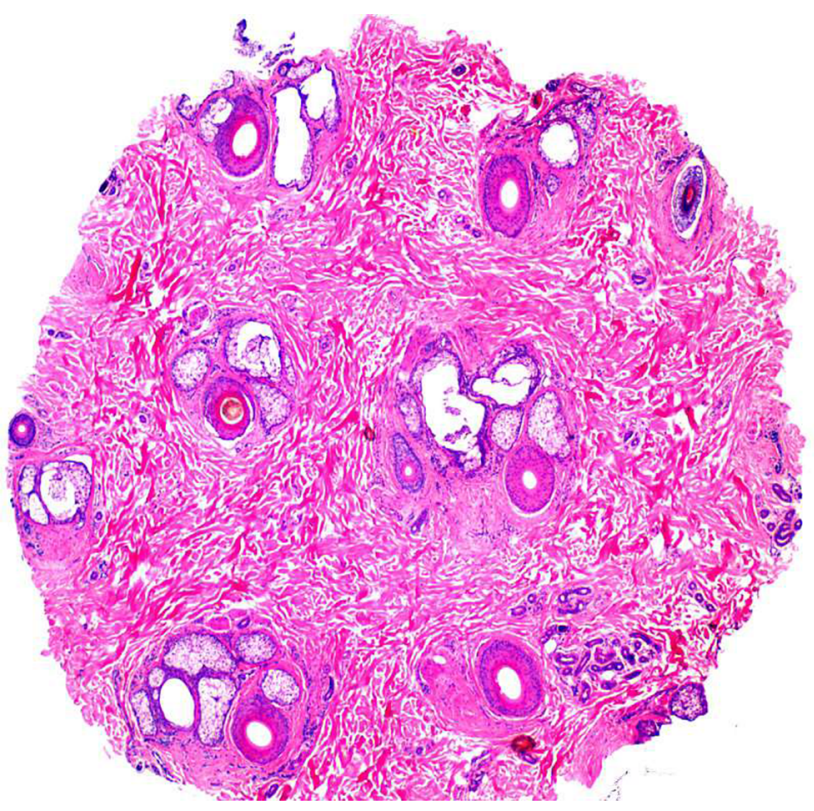

Figure 8 Histology of traction alopecia. On horizontal sections at the level of the isthmus, there is an overall preserved follicular architecture but significantly reduced follicular density (total of nine follicles). The terminal: vellus ratio is $2: I$. The sebaceous glands are mostly preserved (hematoxylin and eosin, $\times 2$ ).

the margin of hair loss, as well as oral and topical antibiotics for their anti-inflammatory properties..$^{21,25,35}$ There are several reports in the literature showing promising results for topical minoxidil in the treatment of advanced TA. Khumaloand Ngwanya reported two cases of women suffering late stage TA who experienced hair regrowth at 3 months and significant hair regrowth after 6 and 9 months, respectively, with the topical application of $2 \%$ minoxidil..$^{42}$ Same patients had previously experienced no response with $1-2$ years of abstention from traumatic hairstyling practices. Additionally, Callender et al reported anecdotal success with topical minoxidil in a subset of TA patients. ${ }^{23}$ Further study is required in order to determine the optimal duration and concentration of minoxidil therapy in the treatment of TA. Although there are no reports on the use of $5 \%$ minoxidil in traction alopecia, it may be considered as an alternative therapeutic option. Latanoprost has not been studied in TA.

The advanced stages of TA, characterized by scarring and follicular atrophy, are less amenable to medical therapy, but surgical treatment through hair transplantation may be an option for some patients. Successful hair transplantation for patients with advanced TA has been documented with multiple techniques, including punch grafting with rotation flaps ${ }^{43}$ micro (1-2 follicular unit grafts), and mini (3-4 follicular unit grafts) grafting. ${ }^{44}$ Ozcelik reported a case of a 23-year-old woman with a 5-year history of wearing an extremely tight ponytail every day in order to elevate her 
Table 2 Summary of the distinguishing clinical, trichosopic, and pathologic findings in patients with patchy alopecias

\begin{tabular}{|c|c|c|c|}
\hline Hair condition & Clinical presentation & Trichoscopy & Pathology \\
\hline Traction alopecia & $\begin{array}{l}\text { Early: localized areas of non- } \\
\text { cicatricial alopecia and hair thinning } \\
\text { around areas of mechanical trauma, } \\
\text { perifollicular erythema, and pustules } \\
\text { Late: localized patches of cicatricial } \\
\text { alopecia in areas undergoing } \\
\text { chronic mechanical trauma }\end{array}$ & $\begin{array}{l}\text { Broken hair shafts } \\
\text { Non-uniform broken hairs } \\
\text { In-brown-outlined follicular } \\
\text { openings marking the empty } \\
\text { follicles } \\
\text { Hair casts }\end{array}$ & $\begin{array}{l}\text { Decreased terminal hairs } \\
\text { Vellus hairs prevail } \\
\text { Sebaceous glands intact } \\
\text { No perifollicular inflammation } \\
\text { No perifollicular fibrosis } \\
\text { Follicular drop out in late stages }\end{array}$ \\
\hline Trichotillomania & $\begin{array}{l}\text { Patches of non-cicatricial alopecia in } \\
\text { accessible areas on scalp } \\
\text { Friar tuck sign } \\
\text { Negative pull test }\end{array}$ & $\begin{array}{l}\text { Broken hairs at different length } \\
\text { Black dots } \\
\text { Flame hairs } \\
\text { "Y-sign" } \\
\text { Tulip hairs } \\
\text { Hook hairs } \\
\text { Hair powder }\end{array}$ & $\begin{array}{l}\text { Increased catagen count (up to } 70 \% \text { ) } \\
\text { Groups of catage/telogen follicles } \\
\text { Trichomalacia } \\
\text { Pigmented casts }\end{array}$ \\
\hline Alopecia areata & $\begin{array}{l}\text { Patches of non-cicatricial alopecia, } \\
\text { variable location } \\
\text { Positive pull test }\end{array}$ & $\begin{array}{l}\text { Exclamation mark hairs } \\
\text { Dystrophic hairs } \\
\text { Black dots } \\
\text { Circle hairs } \\
\text { Yellow dots }\end{array}$ & $\begin{array}{l}\text { Non-scarring alopecia } \\
\text { Peribulbar infiltrate with "swarm of bees" } \\
\text { appearance in the acute stage } \\
\text { Increased telogen count in the subacute stage } \\
\text { Nanogen follicles and vellus follicles in the } \\
\text { chronic stage }\end{array}$ \\
\hline $\begin{array}{l}\text { Patchy central } \\
\text { centrifugal cicatricial } \\
\text { alopecia }\end{array}$ & $\begin{array}{l}\text { Patches of cicatricial alopecia } \\
\text { diffusely throughout scalp but } \\
\text { mostly on parietal scalp }\end{array}$ & $\begin{array}{l}\text { Peripilar white-gray halo } \\
\text { Loss of follicular openings } \\
\text { Irregular pigmented network } \\
\text { White patches } \\
\text { Irregular pin point white dots }\end{array}$ & $\begin{array}{l}\text { Follicular drop-out } \\
\text { Perifollicular fibrosis } \\
\text { Only focal preservation of sebaceous glands } \\
\text { Mild perifollicular inflammation } \\
\text { Premature desquamation of the inner root sheath } \\
\text { Naked hair shafts }\{\text { Miteva, } 2015 \# 137\}\end{array}$ \\
\hline $\begin{array}{l}\text { Frontal fibrosing } \\
\text { alopecia }\end{array}$ & $\begin{array}{l}\text { Frontotemporal band-like cicatricial } \\
\text { alopecia }\end{array}$ & $\begin{array}{l}\text { Peripilar casts } \\
\text { Subtle perifollicular erythema } \\
\text { Absence of follicular openings }\end{array}$ & $\begin{array}{l}\text { Perifollicular fibrosis } \\
\text { Prifollicular lymphohistiocytic lichenoid } \\
\text { inflammation } \\
\text { Follicular drop out } \\
\text { Absence of sebaceous glands } \\
\text { Apoptotic cells in the outer root sheath }\end{array}$ \\
\hline
\end{tabular}

eyebrows who presented with bilateral temporal scarring alopecia and underwent one session of micro- and minigraft transplantation. At 1-year follow-up, the patient had $90 \%-95 \%$ survival of hair at the recipient site with a natural direction of hair growth and reported satisfaction with cosmesis. ${ }^{44}$ With hair transplantation, it is important to counsel the patient on realistic outcomes and likelihood of multiple sessions in order to achieve cosmetically favorable outcomes.

It is of paramount importance that clinicians educating and treating patients with TA remain sensitive and aware of the cultural importance of potentially harmful hairstyling practices.

\section{Future goals}

1. Further research is required to identify the exact pathogenic mechanism of TA including the role of stem cells and genetic factors in the development of the disease.
2. Effective education on prevention, creating community support, and disseminating awareness about TA and risky hairstyling practices among those populations at risk. This is particularly true for the parents of young children who wear traumatic braids and cornrows with/without attached plastic accessories from a very young age.

3. Improved means of detecting those individuals who may be developing TA will allow earliest effective dermatological intervention.

4. Randomized clinical trials will help to develop an evidence base for effective treatment algorithms.

5. While behavioral therapy has shown favorable results in trichotillomania, its value in the management of TA has not studied. Because certain hairstyles are important for cultural identity, public education initiatives targeting the populations with high risk would be the optimal intervention. 


\section{Disclosure}

The authors report no conflicts of interest in this work.

\section{References}

1. Khumalo N, Jessop S, Gumedze F, Ehrlich R. Hairdressing and the prevalence of scalp disease in African adults. Br J Dermatol. 2007;157(5):981-988.

2. Loussouarn G, El Rawadi C, Genain G. Diversity of hair growth profiles. Int J Dermatol. 2005;44(s1):6-9.

3. Khumalo NP, Jessop S, Gumedze F, Ehrlich R. Determinants of marginal traction alopecia in African girls and women. $J$ Am Acad Dermatol. 2008;59(3):432-438.

4. Heath CR, Taylor SC. Alopecia in an ophiasis pattern: traction alopecia versus alopecia areata. Cutis. 2012;89(5):213-216.

5. Hwang SM, Lee WS, Choi EH, Lee SH, Ahn SK. Nurse's cap alopecia. Int J Dermatol. 1999;38(3):187-191.

6. Trebitsch R. Die Krankheiten der Eskimos in West-Grönland. Wiener Klin Wochenschr. 1907;20:1404-1408.

7. Hjorth N. Traumatic marginal alopecia; a special type: alopecia groenlandica. Br J Dermatol. 1957;69(9):319-322.

8. Samrao A, Price VH, Zedek D, Mirmirani P. The "Fringe Sign" - a useful clinical finding in traction alopecia of the marginal hair line. Dermatol Online J. 2011;17(11):1.

9. Krstić A, Konstantinović S, Žunić M, Ilić-Krstić B. Traction alopecia due to traditional hair styles. In: Orfanos CE, Montagna W, editors. Hair Research. Berlin: Springer; 1981:390-391.

10. Costa OG. Traumatic marginal alopecia due to traction on the hair. $\mathrm{Br}$ J Dermatol. 1946;58(11-12):280-286.

11. Spencer GA. Alopecia liminaris frontalis: comment on causation and report of four cases. Arch Dermatol Syphilol. 1941;44(6):1082-1085.

12. Savill A. The nylon brush. Br J Dermatol. 1958;70(8-9):296-299.

13. Child F, Fuller L, Higgins E, Du Vivier A. A study of the spectrum of skin disease occurring in a black population in south-east London. $\mathrm{Br}$ J Dermatol. 1999;141(3):512-517.

14. Khumalo NP, Jessop S, Ehrlich R. Prevalence of cutaneous adverse effects of hairdressing: a systematic review. Arch Dermatol. 2006;142(3):377-383.

15. Khumalo NP. The "fringe sign" for public education on traction alopecia. Dermatol Online J. 2012;18(9):16.

16. Lindelof B, Forslind B, Hedblad MA, Kaveus U. Human hair form Morphology revealed by light and scanning electron microscopy and computer aided three-dimensional reconstruction. Arch Dermatol. 1988;124(9):1359-1363.

17. Herskovitz I, Miteva M. Central centrifugal cicatricial alopecia: challenges and solutions. Clin Cosmet Investig Dermatol. 2016;9:175-181.

18. Bernard BA. Hair shape of curly hair. J Am Acad Dermatol. 2003;48(6 Suppl):S120-S126.

19. Thibaut S, Bernard BA. The biology of hair shape. Int J Dermatol. 2005;(44 Suppl 1):2-3.

20. Haskin A, Aguh C. All hairstyles are not created equal: what the dermatologist needs to know about black hairstyling practices and the risk of traction alopecia (TA). J Am Acad Dermatol. 2016;75(3):606-611.

21. Khumalo N, Jessop S, Gumedze F, Ehrlich R. Hairdressing is associated with scalp disease in African schoolchildren. $\mathrm{Br} J$ Dermatol. 2007;157(1):106-110
22. Wright DR, Gathers R, Kapke A, Johnson D, Joseph CL. Hair care practices and their association with scalp and hair disorders in African American girls. J Am Acad Dermatol. 2011;64(2):253-262.

23. Callender VD, McMichael AJ, Cohen GF. Medical and surgical therapies for alopecias in black women. Dermatol Ther. 2004;17(2):164-176.

24. Bolduc C, Shapiro J. Hair care products: waving, straightening, conditioning, and coloring. Clin Dermatol. 2001;19(4):431-436.

25. McMichael AJ. Hair and scalp disorders in ethnic populations. Dermatol Clin. 2003;21(4):629-644.

26. Grimes PE. Skin and hair cosmetic issues in women of color. Dermatol Clin. 2000;18(4):659-665.

27. James J, Saladi RN, Fox JL. Traction alopecia in Sikh male patients. $J$ Am Board Fam Med. 2007;20(5):497-498.

28. Kanwar AJ, Kaur S, Basak P, Sharma R. Traction alopecia in Sikh males. Arch Dermatol. 1989;125(11):1587-1587.

29. Karimian Teherani D, El shabrawi-Caelen L, Tanew A. Traction alopecia in two adolescent Sikh brothers - an underrecognized problem unmasked by migration. Pediatr Dermatol. 2011;28(3):336-338.

30. Polat M. Evaluation of clinical signs and early and late trichoscopy findings in traction alopecia patients with Fitzpatrick skin type II and III: a single center, clinical study. Int J Dermatol. 2017;56(8): $850-855$.

31. Trüeb R. "Chignon alopecia": a distinctive type of nonmarginal traction alopecia. Cutis. 1995;55(3):178-179.

32. Samrao A, Chen C, Zedek D, Price VH. Traction alopecia in a ballerina: clinicopathologic features. Arch Dermatol. 2010;146(8):918-935.

33. Singh G. Traction alopecia in Sikh boys. Br J Dermatol. 1975;92(2): 232-233.

34. Fox GN, Stausmire JM, Mehregan DR. Traction folliculitis: an underreported entity. Cutis. 2007;79(1):26-30.

35. Lawson CN, Hollinger J, Sethi S, et al. Updates in the understanding and treatments of skin \& hair disorders in women of color. Int JWomens Dermatol. 2017;3(1):S21-S37.

36. Ahdout J, Mirmirani P. Weft hair extensions causing a distinctive horseshoe pattern of traction alopecia. JAm Acad Dermatol. 2012;67(6):e294-e295.

37. Tosti A, Miteva M, Torres F, Vincenzi C, Romanelli P. Hair casts are a dermoscopic clue for the diagnosis of traction alopecia. Br J Dermatol. 2010;163(6):1353-1355.

38. Scott MJ Jr., Roenigk HH Jr. Hair casts: classification, staining characteristics, and differential diagnosis. J Am Acad Dermatol. 1983;8(1):27-32.

39. Sperling LC. Scarring alopecia and the dermatopathologist. $J$ Cutan Pathol. 2001;28(7):333-342.

40. Mirmirani P, Khumalo NP. Traction alopecia. Dermatol Clinics. 2014;32(2):153-161.

41. Scott DA. Disorders of the hair and scalp in blacks. Dermatol Clin 1988;6(3):387-395.

42. Khumalo N, Ngwanya R. Traction alopecia: $2 \%$ topical minoxidil shows promise. Report of two cases. J Eur Acad Dermatol Venereol. 2007;21(3):433-434.

43. Earles RM. Surgical correction of traumatic alopecia marginalis or traction alopecia in black women. J Dermatol Surg Oncol. 1986;12(1):78-82.

44. Özçelik D. Extensive traction alopecia attributable to ponytail hairstyle and its treatment with hair transplantation. Aesthetic Plast Surg. 2005;29(4):325-327.

\section{Clinical, Cosmetic and Investigational Dermatology}

\section{Publish your work in this journal}

Clinical, Cosmetic and Investigational Dermatology is an international, peer-reviewed, open access, online journal that focuses on the latest clinical and experimental research in all aspects of skin disease and cosmetic interventions. This journal is included on PubMed. The manuscript management system is completely online

\section{Dovepress}

and includes a very quick and fair peer-review system, which is all easy to use. Visit http://www.dovepress.com/testimonials.php to read real quotes from published authors 